\title{
COMPARISON OF SEASONAL PREVALENCE OF OTITIS MEDIA WITH EFFUSION (OME) IN MENTALLY HANDICAPPED VERSUS NORMAL SCHOOL-GOING CHILDREN.
}

\footnotetext{
1. MBBS, MCPS, FCPS

Assistant Professor of ENT

Classified ENT Specialist.

Combined Military Hospital,

Abbottabad.

2. MBBS

Medical Officer

Army Burn Hall College for girls

Abbottabad, Khyber Pakhtunkhwa.
}

Correspondence Address: Dr. Nadeem Ahmed Sheikh

Assistant Professor ENT

Combined Military Hospital,

Abbottabad

nadeem_ent75@yahoo.com

Article received on:

17/04/2019

Accepted for publication:

$25 / 08 / 2019$

\begin{abstract}
Nadeem Ahmed Sheikh', Kanwal Nadeem²
ABSTRACT... Objectives: Otitis media with effusion is widespread in pre-school and schoolgoing children. The objective of this study was to compare the prevalence of otitis media with effusion (OME) in normal versus mentally handicapped children in perspective of seasonal variation. Study Design: Randomized controlled trial. Setting: Pakistan Air Force Hospital Masroor, Karachi. Period: January 2015 till August 2016. Material \& Methods: 208 children between 3-8 years of age were divided into 'Mentally Normal' and 'Mentally Handicapped' groups based on a cut off intelligence quotient score of 70 . Results: Otitis media with effusion uniformly affected all school children. Tympanometric pressures from middle ears of both study groups responded indifferently from each other ( $p$ value 0.467 and 0.365 for right middle ear, and 0.708 and 0.920 for left middle ears, in summer and winter, respectively). However, most caregivers of mentally handicapped children exhibited greater concerns about complications associated with otitis media with effusion in winters ( $p$ value 0.002 ). Conclusion: Otitis media with effusion is an insidious condition which remains under diagnosed and adversely affects auditory function and speech. Children may develop this condition regardless of their intellectual status. However craniofacial dysmorphism puts a child at a greater risk of otitis media with effusion. Awareness at primary education and healthcare level, a high index of suspicion in these children, careful examination and prompt referral for expert otologic intervention is pivotal in avoiding complications.
\end{abstract}

Key words: $\quad$ Acoustic Impedance Tests, Disabled Children, Otitis Media with Effusion, Secretory Otitis Media, Season, Tympanometry.

Article Citation: Sheikh NA, Nadeem K. Comparison of seasonal prevalence of Otitis media with effusion (OME) in mentally handicapped versus normal school-going children. Professional Med J 2020; 27(2):309-316.

DOI: 10.29309/TPMJ/2020.27.2.3570

\section{INTRODUCTION}

Otitis media with effusion is defined as accumulation of mucous within the middle ear and sometimes in the mastoid air cell system for more than three months. ${ }^{1}$ The occasional synchronous involvement of the mastoid air cells, perilabyrinthine and petrous apex is attributed to the contiguous pneumatization of these parts of the temporal bone. The condition is usually preceded by one or more episode of acute otitis media. ${ }^{2}$ The problem is global and its frequency is second only to common cold in a pediatric otolaryngology outpatient. ${ }^{3}$ Almost $90 \%$ of children around the world get nonpurulent sero-mucinous fluid collection in their middle ears by the age of five years. 2.2 million new cases are diagnosed in the US annually costing $\$ 4.0$ billions. ${ }^{4,5}$ Major contributory factors are Eustachian tube dysfunction, craniofacial anomalies, allergies and gastro- esophageal reflux. ${ }^{1,6}$ Winter season is known to have been related with a rise in incidence of otitis media with effusion due to increased episodes of upper respiratory infections. ${ }^{7}$ Otitis media with effusion has a bimodal prevalence, i.e. $20 \%$ at two years of age and $16 \%$ around the age of five years. ${ }^{8}$ Influence of Otitis media with effusion on the suffering child's hearing, speech and language development, cognition, behavior, balance and quality of life has largely been studied..$^{9-12}$

Season association with otitis media with effusion in children has less frequently been studied in our region. ${ }^{13-15}$ Little national or regional literature is 
available elaborating a comparative analysis of seasonal prevalence of otitis media with effusion in normal junior school children versus mentally handicapped children of the same age admitted in day-care facilities. ${ }^{16-18}$ The rationale of our study is to establish climatic cold exposure as a risk factor in etiology of otitis media with effusion in healthy as well as mentally handicapped school children; and, to define multidisciplinary clinical guidelines to accurately diagnose and timely manage a ubiquitous yet under-diagnosed otologic condition school children, that may anticipate a long lasting physical, social and psychological disability.

\section{PATIENTS \& METHODS}

After seeking approval from the hospital research ethics committee and the institutional executive body, we requested parents of school-going children between ages 3 to 8 years to provide us a written informed consent for their children to be included in the study. Children from Saleem Nawaz Fazaia College and Pakistan Air Force Women Association (PAFWA) Special Children Academy, PAF Masroor, Karachi were included.

We randomly included 3 to 8 years old children regardless of gender, parental literacy, and socioeconomic class. Children with cleft palate, acute suppurative otitis media, chronic otitis media or sensorineural hearing loss were excluded. Almost 5500 children aged 3-8 years reside in territory of PAF Masroor, Karachi. For research, we kept the confidence level at 95\%, and the margin of error at $5 \%$, and the sample size for finite universe (population) turned out to be 199.

We obtained a detailed history from the parents of 208 children, and they were asked to fill in the checklist-based OM-6 validated questionnaire (annexure-1). All children were categorized into two groups basing on modified Urdu translated version of Wechsler Preschool \& Primary Scale of Intelligence-IV edition (WPPSI-IV) psychometric assessment. Children who acquired score of 70 and above were mentally normal and were included in Group-1.
Those who obtained a lesser score than 70 were allocated Group-2, categorized as intellectually disabled children. These children were clinically examined in the months of December and January, and subsequently followed in June and July. We performed otoscopic examination on every child using pneumatic bulb attached to Reister otoscope and, tympanometry using MAICO MI24 digital tympanometer and maintained a record of individual finding in our database.

Data analysis was performed using statistical program for social science IBM-SPSS version-22. Frequencies were measured by applying descriptive statistics. Group difference in mean tympanometry and OM-6 symptom scores were evaluated using independent sample t-test. Paired sample t-test was applied to compare these scores in summer and winters. The level of statistical significance in order to prove our hypothesis was 0.05 .

\section{RESULTS}

Of the 208 children included in the study, the youngest was 3 years old and the oldest was 8.5 years. Mean age was 5.227 years ( $S D \pm 1.39$ ). $79.3 \%(n=165)$ children achieved a WPSSI-IV score of equal or more than 70 , and they were included in Group-1.

Remaining $20.7 \%(n=43)$ were categorized as mentally handicapped, and were allocated the Group-2. 7.2\% $(n=15)$ children had associated cranio-facial dysmorphism, majority suffering from Down syndrome.

Figure-1

\section{Age Distribution}

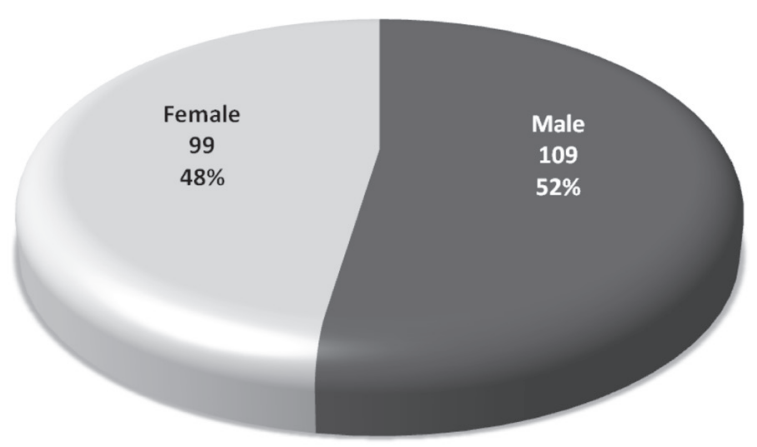


We recorded a mean middle ear pressure of -14.48 daPa (SD \pm 75.187$)$ and -13.94 daPa $(S D \pm 81.464)$ in right and left ears, in summer, respectively. Middle ear pressures in right and left ears in winter turned out to be $-22.97 \mathrm{daPa}$ $(\mathrm{SD} \pm 74.666)$ and $-29.97 \mathrm{daPa}(\mathrm{SD} \pm 83.767)$, respectively.

Likewise, mean compliance of middle ear in summer months came out to be $0.436 \mathrm{~cm}^{3}$ $(S D \pm 0.332)$ and $0.438 \mathrm{~cm}^{3}(S D \pm 0.331)$ in right and left ears.

Tympanometry showed the middle ear compliance in winter as $0.377 \mathrm{~cm}^{3}$ (SD \pm 0.294$)$ and $0.329 \mathrm{~cm}^{3}(S D \pm 0.257)$ on right and left sides, respectively. We found a significant decrease in the pressure recordings in summer and winter $(p$ value 0.007 and 0.000 in right and left middle ears, respectively). Similarly tympanometry confirmed a significantly low middle ear compliance in winters ( $p$ value 0.000 and 0.000 on right and left sides, respectively).

Applying indpendent samples t-test, the group statistics revealed significant difference with a markedly high negative pressures in middle ears of children having cranio-facial dysmorphism, as compared to their normal counterparts. Table-I.

Out of the middle ear pressures and compliances, when study groups 1 and 2 were weighed against each other in both seasons, we could only see a significant difference in the mean compliance score of right ear, which strikingly turned out to be much low in normal children against those who were intellectually handicapped. Table-II. Not much considerable statistical dissimilarity was observed when the remaining parameters between the two groups were studied in summer and winter.

Children who displayed normal intellectual abilities suffered from lesser physical disability than their mentally handicapped counterparts throughout the year ( $p$ values 0.016 and 0.003 in summer and winter). In terms of hearing loss and speech impairment, Group-1 children suffered less than those from Group-2 in both seasons ( $p$ values for hearing loss and speech impairment, 0.000 in both seasons respectively).

We did not see much distinction in emotional distress and activity limitation between the children of the two groups, round the year ( $p$ value for emotional distress between the two groups were 0.944 and 0.609 ; and for activity limitation were 0.703 and 0.703 in summer and winter, respectively).

Caregivers expressed high concerns on mentally handicapped children in winter ( $p$ value 0.002), however indiscrimnate concerns were given away by the caregivers toward children of both study groups in summer ( $p$ value 0.243 ). Table-III

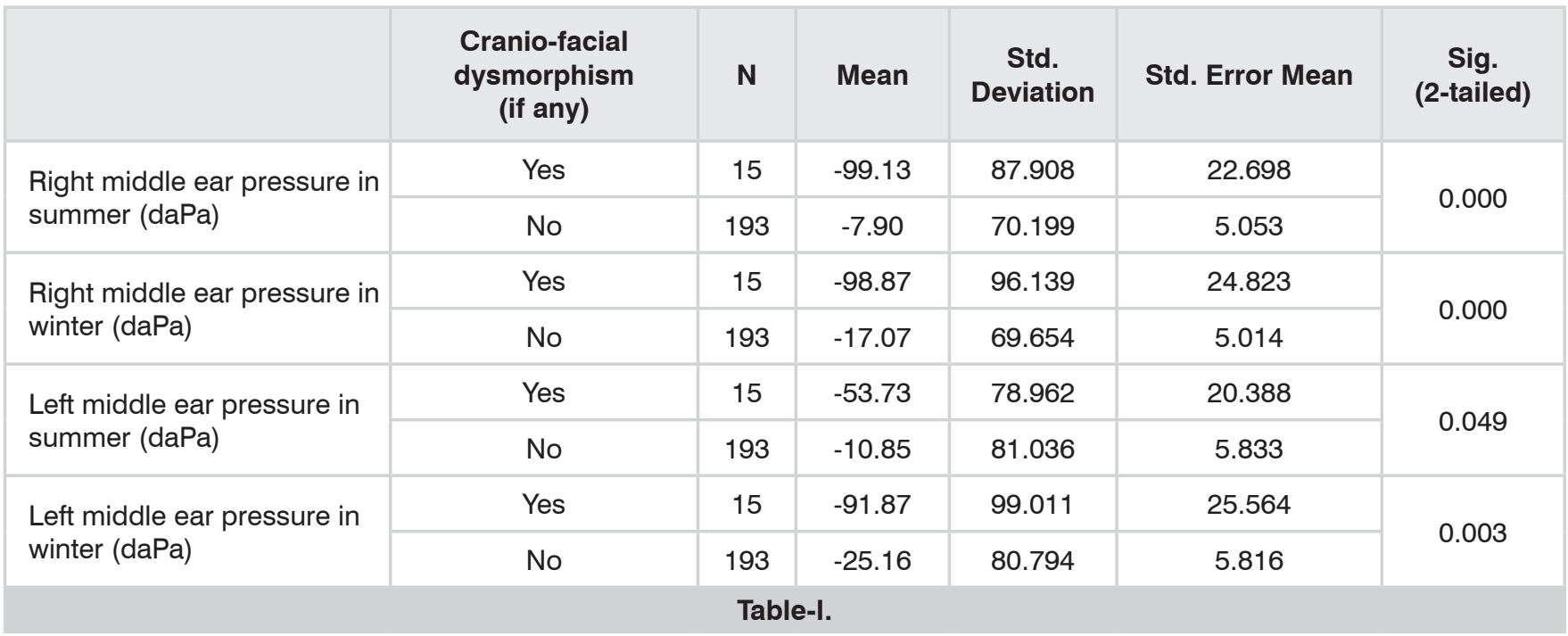




\begin{tabular}{|c|c|c|c|c|c|c|}
\hline & Study group & $\mathbf{N}$ & Mean & $\begin{array}{l}\text { Std. } \\
\text { Deviation }\end{array}$ & $\begin{array}{l}\text { Std. Error } \\
\text { Mean }\end{array}$ & $\begin{array}{l}\text { Sig. } \\
\text { (2-tailed) }\end{array}$ \\
\hline $\begin{array}{l}\text { Right middle ear pressure in } \\
\text { summer (daPa) }\end{array}$ & Normal & 165 & -12.54 & 72.879 & 5.674 & 0.467 \\
\hline \multirow{2}{*}{$\begin{array}{l}\text { Right middle ear pressure in } \\
\text { winter }(\mathrm{daPa})\end{array}$} & Normal & 165 & -20.57 & 72.304 & 5.629 & \multirow{2}{*}{0.365} \\
\hline & Mentally handicapped & 43 & -32.19 & 83.390 & 12.717 & \\
\hline $\begin{array}{l}\text { Left middle ear pressure in } \\
\text { summer }(\mathrm{daPa})\end{array}$ & Mentally handicapped & 43 & -9.79 & 97.909 & 14.931 & 0.708 \\
\hline \multirow{2}{*}{$\begin{array}{l}\text { Left middle ear pressure in } \\
\text { winter (daPa) }\end{array}$} & Normal & 165 & -29.67 & 81.731 & 6.363 & \multirow{2}{*}{0.920} \\
\hline & Mentally handicapped & 43 & -31.12 & 92.187 & 14.058 & \\
\hline \multirow{2}{*}{$\begin{array}{l}\text { Right middle ear compliance in } \\
\text { summer (ml3) }\end{array}$} & Normal & 165 & .4126 & .32358 & .02519 & \multirow{2}{*}{0.045} \\
\hline & Mentally handicapped & 43 & .5265 & .35299 & .05383 & \\
\hline \multirow{2}{*}{$\begin{array}{l}\text { Left middle ear compliance in } \\
\text { summer }(\mathrm{ml} 3)\end{array}$} & Normal & 165 & .4301 & .31072 & .02419 & \multirow{2}{*}{0.502} \\
\hline & Mentally handicapped & 43 & .4684 & .40507 & .06177 & \\
\hline \multirow{2}{*}{$\begin{array}{l}\text { Left middle ear compliance in } \\
\text { winter (ml3) }\end{array}$} & Normal & 165 & .3119 & .23433 & .01824 & \multirow{2}{*}{0.058} \\
\hline & Mentally handicapped & 43 & .3956 & .32844 & .05009 & \\
\hline
\end{tabular}

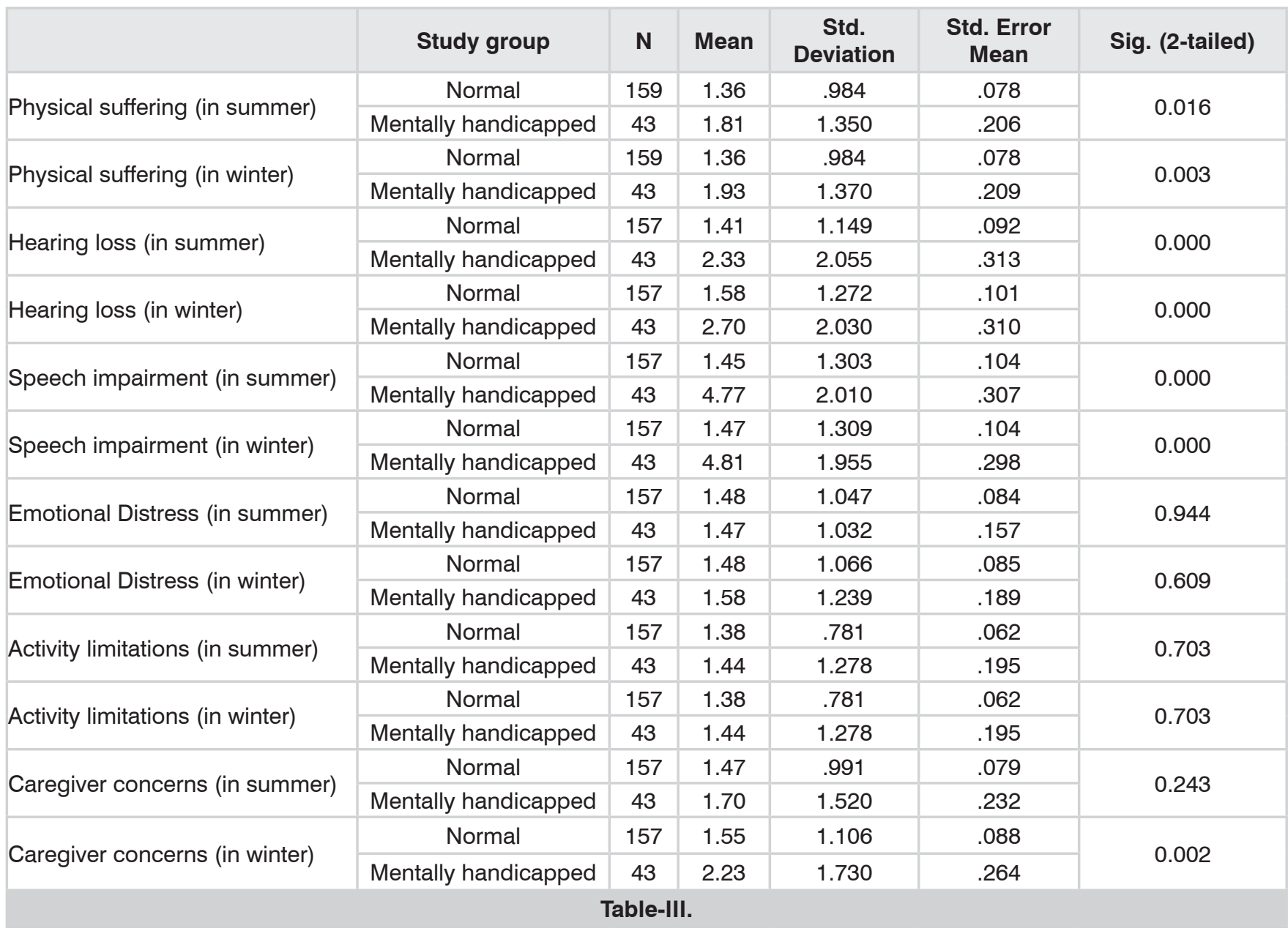




\section{DISCUSSION}

Development of middle ear effusion is an insidious process attributable to two schools of thought. Eustachian tube dysfunction comprising of ciliary dysfunction and mucosal edema, possibly consequent to anatomical obstruction, allergies or an episode of rhino sinusitis, is the forerunner of production and accumulation of a serous transudate from the mucosa. This is precipitated by unfavorable pressure gradient across the Eustachian tube created by continuous absorption and diffusion of nitrogen and oxygen into the mucosal vasculature. A Eustachian tube with impaired drainage further adds to microbial proliferation in stagnant transudate. $45 \%$ of children develop persistent effusion in middle ear one month after an episode of acute otitis media. Recent researchers have used polymerase chain reaction (PCR) technology to identify microbial biofilm in $48 \%$ of culture negative middle ear effusions. ${ }^{19}$ However Bluestone and Crapko described another model of development of otitis media with effusion. They describe the development of mucosal inflammation due to a reaction to bacteria already present in middle ear. ${ }^{20,21}$ Tasker discovered pepsinogen levels 1000 times higher that of serum, in more than $90 \%$ of effusion collection during tympanostomies. ${ }^{22}$ Yilmaz et al highlighted a possibility of significant role of oxidants and anti-oxidants in pathogenesis of chronic tonsillitis, adenoid hypertrophy and otitis media with effusion, since the blood levels of oxidants and antioxidants improved after surgical intervention. ${ }^{23}$ In children with congenital cleft palate, the anomalous insertion of tensor veli palatini muscle into the soft palate results in inability to open the Eustachian tube orifice upon swallowing.

Though the frequency of otitis media with effusion declines with advancing age, other significant contributory factors include parental smoking, recent episodes of upper respiratory tract infections and acute otitis media, parental illiteracy, low socio-economic status, number of siblings and attending daycare facilities. ${ }^{24-26}$ Birth weight, gestational age and breast feeding also have displayed a significant association. ${ }^{27}$ However some older researches have shown a weak correlation with parental smoking, family history of otitis media and parental socioeconomic status. ${ }^{27}$ High fat diet has also been shown as a confounder in between obesity and otitis media with effusion. ${ }^{28}$

We had requested all the parents and caregivers of the children to complete the OM-6 questionnaire during their first visit to the outpatient. ${ }^{29}$ The OM6 , developed in 1997, is a simple, valid, reliable and most frequently used instrument to evaluate quality of life in children suffering from otitis media with effusion. ${ }^{30,31}$

Generally morbidity associated with respiratory tract infections increases in winters. Incidence of otitis media with effusion is highest in fall and winter. $^{32}$ Climatic hypothermia of the body surface jeopardizes nasal airway defense mechanism by inducing a reflex vasoconstriction of the respiratory mucosa. The resultant mucosal dehydration decreases the number of leukocytes and cytokines therein..$^{33}$ Subsequently impaired mucocilliary clearance and diminished leukocyte-dependent phagocytosis stalls the upper respiratory tract imperviousness against infections. ${ }^{34-37}$ Advent of polymerase chain reaction ( $\mathrm{PCR}$ ) has paved way to the detection of respiratory viruses in specimens from acute otitis media. ${ }^{8}$

A significant surge in respiratory tract infections is obvious in our setup in winter. Mauripur is located along the Arabian Sea coast of Karachi where temperature drops to $11^{\circ} \mathrm{C}$ in the months of December and January. It may soar as high as $46^{\circ} \mathrm{C}$ in the months of June and July. Although highest prevalence of otitis media with effusion has been observed in preschool children in the month of April, and the lowest in October. More studies based in the UK reported a rise in prevalence in winter months. ${ }^{38,39}$

\section{CONCLUSION}

Otitis media with effusion is more prevalent in winter months in normal primary school children as well as mentally handicapped children with special needs, of the same age. The condition puts lasting impact on the auditory and 
communication system of mentally handicapped children. Delay in diagnosis predisposes these children to the risk of developing physical and social disability in terms of conductive hearing loss and poor speech development; and, puts psychological constraint on their parents. Primary care clinicians must stress on obtaining pertinent clinical history, develop skill to perform otoscopic examination whenever needed and prompt referral to specialized Ear Nose \& Throat clinic for expert investigation and appropriate management.

Copyright@ 25 Aug, 2019.

\section{REFERENCES}

1. Browning G. Otitis media with effusion. In: Gleeson $M$, editor. Scott-Brown's Otorhinolaryngology, Head and Neck Surgery Volume-1. London: Hodder Arnold Publishing; 2008. p. 877.

2. Lok W, Anteunis LJ, Chenault MN, Meesters C, Haggard MP. Screening for hearing loss versus parental concern regarding hearing problems: Subsequent referral and treatment for otitis media in the Netherlands. Scandinavian journal of primary health care. 2012; 30(3):163-8.

3. Casselbrant ML, Mandel EM. Otitis media with effusion. Encyclopedia of Otolaryngology, Head and Neck Surgery: Springer; 2013. p. 1971-8.

4. Frellick M. Otitis Media: New guideline includes screening at-risk kids [Internet]. [Place Unknown]: Medscape Medical Reviews; 2016 [Updated 2016 February 4, and cited 2016 March 13]. Available from: http://www.medscape.com/viewarticle/858307.

5. Rosenfeld RM et al. Clinical practice guidelines: Otitis media with effusion executive summary (update). Otolaryngol Head Neck Surg. 2016; 154:201-214.

6. Neto JFL, Sih T. Risk factors for recurrent acute otitis media and chronic otitis media with effusion in childhood. Otitis Media: State of the art concepts and treatment: Springer; 2015. p. 23-32.

7. Yousaf M, Inayatullah, Ahmad N, Ali S. The presentation pattern of otitis media with effusion. J Med Sci. 2009; 17(1):53-5.

8. Coleman A, Wood A, Bialasiewicz S, Ware RS, Marsh RL, Cervin A. The unsolved problem of otitis media in indigenous populations: A systematic review of upper respiratory and middle ear microbiology in indigenous children with otitis media. Microbiome. 2018; 6(1):199.
9. Rosenfeld RM, Culpepper L, Doyle KJ, Grundfast KM, Hoberman A, Kenna MA, et al. Clinical practice guideline: Otitis media with effusion. OtolaryngologyHead and Neck Surgery. 2004; 130(5):S95-S118.

10. Teele DW, Klein JO, Chase C, Menyuk P, Rosner BA, Group GBOMS. Otitis media in infancy and intellectual ability, school achievement, speech, and language at age 7 years. Journal of Infectious Diseases. 1990; 162(3):685-94.

11. Harman NL, Bruce IA, Kirkham JJ, Tierney S, Callery $\mathrm{P}, \mathrm{O}$ 'Brien $\mathrm{K}$, et al. The importance of integration of stakeholder views in core outcome set development: Otitis media with effusion in children with cleft palate. PloS one. 2015; 10(6):e0129514.

12. Haapala S, Niemitalo-Haapola E, Raappana A, Kujala T, Suominen K, Kujala T, et al. Effects of recurrent acute otitis media on cortical speech-sound processing in 2-year old children. Ear and hearing. 2014; 35(3):e75-e83.

13. Surapaneni H, Sisodia SS. Incidence of ear, nose and throat disorders in children: A study in a teaching hospital in Telangana. International Journal of Otorhinolaryngology and Head and Neck Surgery. 2016; 2(1):26-9.

14. Jabeen T, Malik SN, Chattha RU. Frequency of secretory otitis media in children of age 3 to 5 years in Rawalpindi and Islamabad. Rawal Medical Journal. 2013; 38(1):52-5.

15. Malik SA, Muhammad R, Yousaf M, Shah I. Effectiveness of conservative treatment in the management of secretory otitis media. Journal of Ayub Medical College, Abbottabad: JAMC. 2014; 26(3):337.

16. Austeng $\mathrm{ME}$, Akre $\mathrm{H}$, Øverland $\mathrm{B}$, Abdelnoor $\mathrm{M}$, Falkenberg E-S, Kværner KJ. Otitis media with effusion in children with in Down syndrome. International journal of pediatric otorhinolaryngology. 2013; 77(8):1329-32.

17. Adams DJ, Susi A, Erdie-Lalena CR, Gorman G, HisleGorman E, Rajnik M, et al. Otitis media and related complications among children with autism spectrum disorders. Journal of autism and developmental disorders. 2016:1-7.

18. Hogan A, Phillips RL, Howard D, Yiengprugsawan V. Psychosocial outcomes of children with ear infections and hearing problems: A longitudinal study. BMC pediatrics. 2014; 14(1):65.

19. Walker RE, Bartley J, Flint D, Thompson JM, Mitchell EA. Determinants of chronic otitis media with effusion in preschool children: A case-control study. BMC pediatrics. $2017 ; 17(1): 4$. 
20. Abtahi SH, Kazerooni A, Brejis N, Abdeyazdan Z, Saneian $H$. Prevalence and characteristics of gastroesophageal reflux in children with otitis media in Isfahan, Iran. Advanced biomedical research. 2016;5.

21. Huyett $P, \operatorname{Raz} Y$, Hirsch BE, McCall AA. Radiographic mastoid and middle ear effusions in intensive care unit subjects. Respiratory care. 2017; 62(3):350-6.

22. Doğru M, Kuran G, Haytoğlu S, Dengiz R, Arıkan OK. Role of laryngopharyngeal reflux in the pathogenesis of otitis media with effusion. J Int Adv Otol. 2015; 11(1):66-71.

23. Aydin S, Demir MG, Oguztuzun S, Kilic M, Yilmaz C, Dirican $O$. Glutathione S-transferase enzyme activity and protein expression in patients with recurrent tonsillitis and idiopathic tonsillar hypertrophy. 2019.

24. Martines F, Salvago P, Ferrara S, Messina G, Mucia M, Plescia $F$, et al. Factors influencing the development of otitis media among Sicilian children affected by upper respiratory tract infections. Brazilian journal of otorhinolaryngology. 2016; 82(2):215-22.

25. Hosseini S, Khajavi M, Eftekharian A, Akbari N. Vitamin $D$ levels in children with otitis media with effusion: $A$ case-control study. Thrita. 2016; 5(1).

26. Chadha S, Sayal A, Malhotra V, Agarwal A. Prevalence of preventable ear disorders in over 15000 schoolchildren in northern India. The Journal of Laryngology \& Otology. 2013; 127(1):28-32.

27. Harkare VV, Aarzoo VV, Khadakkar SP, Deosthale NV. Prevalence and Risk Factors of Otitis Media with Effusion among Children. Prevalence. 2018 Jul;11(2):10-5.

28. Choi HG, Sim S, Kim SY, Lee H-J. A high-fat diet is associated with otitis media with effusion. International journal of pediatric otorhinolaryngology. 2015; 79(12):2327-31.

29. Grindler DJ, Blank SJ, Schulz KA, Witsell DL, Lieu JE. Impact of otitis media severity on children's quality of life. Otolaryngology--Head and Neck Surgery. 2014; $151(2): 333-40$.

30. Demant MN, Jensen RG, Jakobsen JC, Gluud C, Homøe $P$. The effects of ventilation tubes versus no ventilation tubes for recurrent acute otitis media or chronic otitis media with effusion in 9 to 36 month old Greenlandic children, the SIUTIT trial: Study protocol for a randomized controlled trial. Trials. $2017 ; 18(1): 30$.
31. Milovanovic J, Filipovic SA, Marchisio P, Haggard MP, Zhang MF, Spencer H, et al. Precision-scored parental report questions and HL-scaled tympanometry as informative measures of hearing in otitis media 1: Large-sample evidence on determinants and complementarity to pure-tone audiometry. International journal of pediatric otorhinolaryngology. 2016; 83:113-31.

32. Dewan K, Lieu J. A clinical trial of proton pump inhibitors to treat children with chronic otitis media with effusion. J Int Adv Otol. 2018; 14(2):245-9.

33. Walsh NP, Oliver SJ. Exercise, immune function and respiratory infection: An update on the influence of training and environmental stress. Immunology and cell biology. 2016; 94(2):132-9.

34. Khalid A, Baqai T, Bukhari M, Khan MM. Comparison of the incidence of tuberculosis in different geographical zones in the state of Jammu and Kashmir. Pakistan Journal of Chest Medicine. 2015; 19(1).

35. Baumgardner DJ. The value in verifying medical folklore. Journal of Patient-Centered Research and Reviews. 2017; 4(3):101-3.

36. Gasparrini A, Guo Y, Hashizume M, Lavigne E, Zanobetti A, Schwartz J, et al. Mortality risk attributable to high and low ambient temperature: A multi-country study. The Lancet. 2014.

37. Ishmatov AN. Why respiratory viruses or bacteria have the highest probability to be deposited in the respiratory tract in flu seasons. PeerJ Preprints; 2016. Report No.: 2167-9843.

38. Zernotti ME, Pawankar R, Ansotegui I, Badellino $\mathrm{H}$, Croce JS, Hossny $E$, et al. Otitis media with effusion and atopy: Is there a causal relationship? World Allergy Organization Journal. 2017; 10(1):37.

39. Khilnani AK, Prajapati V. Study of clinical and demographic profile of patients diagnosed with secretory otitis media. International Journal of Otorhinolaryngology and Head and Neck Surgery. 2017; 3(3):715. 


\begin{tabular}{|c|c|c|c|}
\hline \multicolumn{3}{|c|}{ AUTHORSHIP AND CONTRIBUTION DECLARATION } \\
\hline Sr. \# & Author(s) Full Name & \multicolumn{1}{c|}{ Contribution to the paper } & Author(s) Signature \\
\hline 1 & Nadeem Ahmed Sheikh & $\begin{array}{l}\text { Conceptualization, literature } \\
\text { search, methodology, } \\
\text { data collection, statistical } \\
\text { analysis, write-up, proof } \\
\text { reading. } \\
\text { Data collection. }\end{array}$ \\
\hline 2 & Kanwal Nadeem &
\end{tabular}

